\title{
PARTICIPATION OF UNIVERSITY STUDENTS IN NON-FORMAL LIFELONG LEARNING PROGRAMS: TYPES OF PROGRAMS, REASONS FOR PARTICIPATION AND THE IMPORTANCE OF LEARNING OUTCOMES IN THEIR STUDENT, PROFESSIONAL, PERSONAL, AND SOCIAL LIFE
}

\author{
Pavlis-Korres Maria ${ }^{\mathrm{i}}$ \\ Associate Professor, SEDEd, \\ Aristotle University of Thessaloniki,
}

Greece

\begin{abstract}
:
In the context of lifelong learning, non-formal education programs are increasingly gaining ground, as they both address weaknesses in the formal education system and help learners respond to new demands that arise in the course of their lives. The present study investigates, through a qualitative approach, the participation of 97 students of the Department of Early Childhood Education (Aristotle University of Thessaloniki) in nonformal adult education programs. Our findings indicate that all students do participate in non-formal education programs, selecting the programs mainly related to education that will complement and facilitate their university studies, as well as enhance their formal and substantive qualifications as early childhood educators. In addition, they participate in programs to make creative use of their leisure time, to create and develop their social networks, but also for the joy of learning something new. Regarding the importance of the learning outcomes they acquire, students focus mainly on attitudes and skills, making it clear that in addition to instrumental knowledge, they also anticipate the acquisition of communicative and emancipatory knowledge.
\end{abstract}

Keywords: non-formal education, motives of participation, learning outcomes

\section{Introduction}

As part of the course Design of Non-formal Education Programs at the Department of Early Childhood Education (Aristotle University of Thessaloniki), students examine issues related to lifelong learning, adult and non-formal education. This paper investigates the participation of students, who attended this course in the winter semester of the academic year (2020-2021), in non-formal education programs. It sets out to present

'Correspondence: email mariapavliskorres@nured.auth.gr, mariapavliskorres@gmail.com 
their reasons for participating in non-formal education programs, the type of programs they chose to attend, and the importance of learning outcomes for them.

This paper first addresses the basic concepts of lifelong learning and the reasons for participating in non-formal adult education programs. The research methodology followed for data collection and processing is then analyzed, followed by the presentation and the discussion on the main findings and conclusions of the research.

\section{Literature Review}

Lifelong learning includes all learning activities in a person's life throughout his or her life span. It includes formal and non-formal education and informal learning. The term is often identified with adult education and non-formal education programs, which take up a large part it, as the largest number of non-formal education programs take place after the completion of secondary education. Non-formal education is characterized by its flexibility both in terms of its content, usually determined by a prior needs' assessment of the target population and its flexibility in terms of time, place and the active educational methods used. Non-formal education occasionally comes to fill the gaps observed in the formal system (Rogers, 2004) or to offer the possibility of updating and/or acquiring new knowledge and skills, with a view to help individuals integrate into the workplace, advance their professional development, and enhance their employability. It also provides them with opportunities to make better use of their leisure time and contributes to their personal fulfilment, civic participation and active citizenship development (Jarvis, 2002; Coombs \& Ahmed, 1974; Pavlis Korres \& Lefteriotou, 2020).

Nowadays, non-formal education is considered an integral part of education in both developing and developed countries, offering opportunities to update qualifications or acquire new skills in the context of lifelong education and learning with a view to enhancing the employability of adults and their participation in economic and social life. The 1999 Declaration of the Parliamentary Assembly of the Council of Europe (Report Doc 8595, 15 Dec, 1999) recognizes that formal educational systems alone cannot respond to the challenges of modern society and therefore welcomes its reinforcement by nonformal education. It further recommends that governments and competent authorities of the Member States recognize non-formal education as a 'de facto' partner in the lifelong learning process and make it accessible to all. Particular reference is also made to the use of new technologies in the context of non-formal education and to ensuring easy access to them at the national and international level.

According to UNESCO (2012, p. 81) non-formal education is defined as "Education that is institutionalized, intentional and planned by an education provider. The defining characteristic of non-formal education is that it is an addition, alternative and/or a complement to formal education within the process of the lifelong learning of individuals. It is often provided to guarantee the right of access to education for all. It caters for people of all ages, but does not necessarily apply a continuous pathway-structure; it may be short in duration and/or low 
PARTICIPATION OF UNIVERSITY STUDENTS IN NON-FORMAL LIFELONG LEARNING PROGRAMS: TYPES OF PROGRAMS, REASONS FOR PARTICIPATION AND THE IMPORTANCE OF LEARNING OUTCOMES IN THEIR STUDENT, PROFESSIONAL, PERSONAL, AND SOCIAL LIFE

intensity, and it is typically provided in the form of short courses, workshops or seminars. Nonformal education mostly leads to qualifications that are not recognized as formal qualifications by the relevant national educational authorities or to no qualifications at all. Non-formal education can cover programmes contributing to adult and youth literacy and education for out-of-school children, as well as programmes on life skills, work skills, and social or cultural development."

Considering the lifewide and lifelong nature of non-formal education, according to the relevant literature, adults participate in educational programs for more than one reason and wish to directly apply the knowledge acquired in the program in order to adapt to changes in their lives (Tough, 1968; Aslanian \& Briekel, 1980; Rogers, 2004;). In addition, Rogers and Horrocks (2012) identify two common characteristics in adult participation in educational programs: "first, the participants are almost always voluntary learners [...] and secondly, they have come with an agenda, an intention, in most cases to achieve a learning goal" (p.17-18).

In the relevant literature, there is a plethora of categorizations and approaches to the reasons behind adult participation in educational programs. Without there being a simple formula to answer the question of why adults participate in educational programs, we can support "that motives differ for different groups of learners, at different stages of life, and most individuals have not one but multiple reasons for learning" (Cross, 1981, p.97). The reasons for participating in educational programs can be related to work and career advancement, development of social relationships, external expectations, social contribution, an attempt to flee away from other situations, an interest in gaining knowledge and learning a subject, improvement of communication skills, amelioration of family relationships (Boshier, 1971; Boshier \& Collins, 1985; Morstain \& Smart, 1974; Fujita-Starck, 1996; Cross, 1981). Cross (1981) makes a significant point about adult participation in non-formal education, arguing that learning is addictive; "the more education people have, the more they want, and the more they will get" (p.55). Therefore, participation is directly related to the educational level of the individual, as it is argued that "young people who advance further in the formal educational system are the most active learners as adults" (Cross, 1981, p. 54), since they are more interested in further education, they will know more about available opportunities, and they will participate more in educational programs. In addition, many researchers have linked adults' participation to their social, political, economic and cultural characteristics, highlighting, thus, the nonneutrality of education in reproducing social and educational inequalities (London, 1970; Knipparth \& DeRick, 2015; Dourgounas, 2021).

According to Eurostat data, participation of adults (24-64 years old) in adult education programs has increased between 2010 and 2019 from $7.8 \%$ to $10.8 \%$ but fell by $1.6 \%$ to $9.2 \%$ in 2020 (Eurostat, 2020). The target set under the strategic framework for European cooperation and training, according to which, at a European level, an average of at least $15 \%$ of adults should participate in lifelong learning by 2020, has not been reached, as only six countries are found to have percentages above the target: Sweden (28.6\%), Finland (27.3\%), Denmark (20\%), the Netherlands (18.Denmark (27.27\%), 
Denmark (20\%), Denmark (18.8\%), Estonia (17.1\%), and Luxembourg (16.3\%), while seven Member States, including Greece, are below 5\%: Romania (1\%), Bulgaria (1.6\%), Slovakia (2.8\%), Croatia (3.2\%), Poland (3.7\%), Greece (4.1\%), and Cyprus (4.7\%).

In addition, according to Eurostat data for 2019, participation in adult programs is directly related to educational level: in the EU-27 on average only $4.3 \%$ of adults with the lowest levels of qualifications participated in education and training, those with medium level qualification participated on average $8.5 \%$, whereas the rate among those with tertiary education degree was $18.7 \%$ (European Commission/EACEA/Eurydice, 2021). It is therefore of particular importance to investigate key data on undergraduate students' participation in non-formal adult education programs in Greece, such as the type of programs and the reasons for attending them.

In Greece, according to the studies conducted by Karalis (2021) from 2011 to 2019 on the motivations and barriers to the participation of adults in educational programs, the following are consistently highlighted among the ten primary reasons stated by the participants. On the one hand, participants relate their attending programs with work ("to be more efficient in my work", "to increase my financial earnings", "to keep my job", "to increase my qualifications", "to find a better job") and on the other hand with their desire for lifelong learning and acquiring knowledge about new things ("because I like to learn new things" and "because education should last during all our lives"). In addition, in lower percentages, participants refer to the creation and improvement of social relations ("to meet new people and improve my social network"), their self-fulfillment as citizens and the acquisition of a certificate.

\section{Methodology of the Research}

The aim of this research was to investigate the key elements of undergraduate students' participation in lifelong learning programs during their studies. The research questions concerned the type of programs students attended and the reasons behind their attendance, as well as whether they considered the knowledge, skills and attitudes they acquired by participating in the programs to be important (Figure 1).

A qualitative approach was implemented for the data collection of this research. Students were asked to recall their experiences in relation to non-formal education programs they had attended and then to select one of these programs, describe its key elements, indicate the reasons for attending it, and whether they considered the learning outcomes to be important in their lives. 


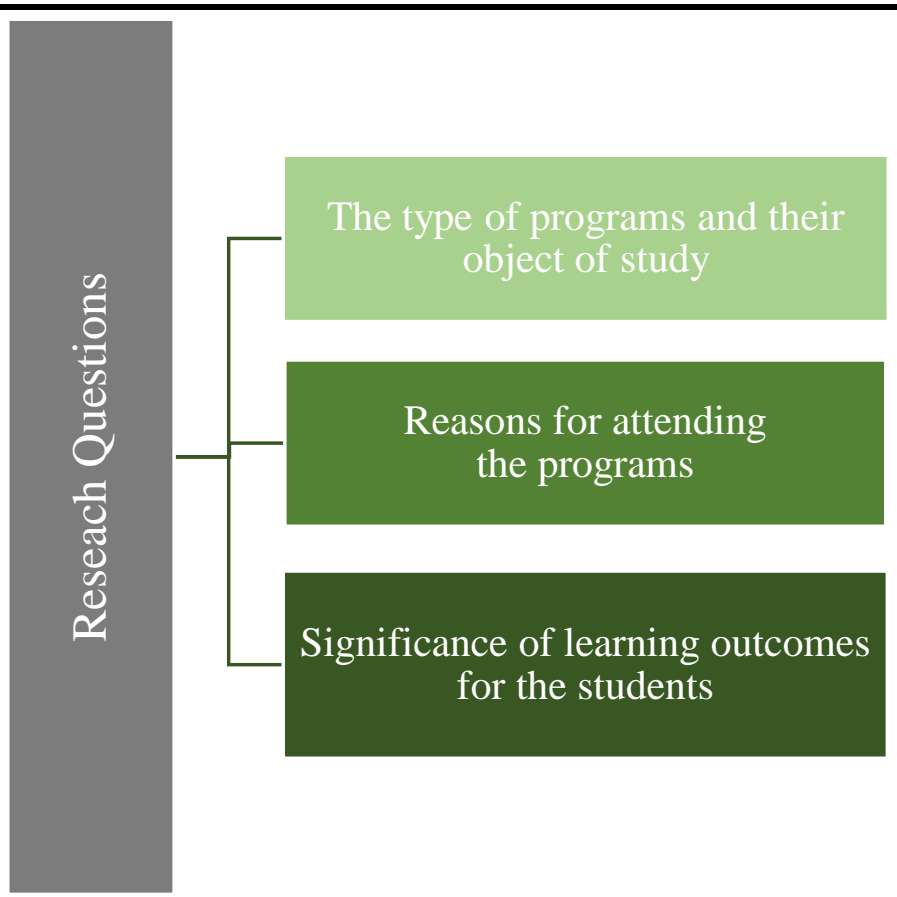

Figure 1: Research questions to be investigated

The study included 97 students who are in their third and fourth year of studies during the academic year 2020-2021. The experience recall was conducted at the end of the semester to ensure that the students had previously familiarized themselves with the basic concepts related to non-formal education and the design of non-formal education programs. They were asked to complete a questionnaire with open-ended questions and thematic analysis (Braun \& Clark, 2013) was used to analyze the data, the results of which are presented and discussed below.

\section{Results and Discussion}

The thematic analysis of the data revealed that all the undergraduate students participating in the study have had an experience of non-formal education programs and attend programs alongside their studies. The findings confirm what Cross (1981) argues in relation to learning being addictive and that participation is related to the educational level of the individuals. Students participate in a variety of educational programs related to their student and professional identity, as well as the better use of their leisure time and the development of their social relationships. The types of programs that emerged from the thematic analysis in relation to their object of study of the programs they choose to participate in are illustrated in Figure 2. 


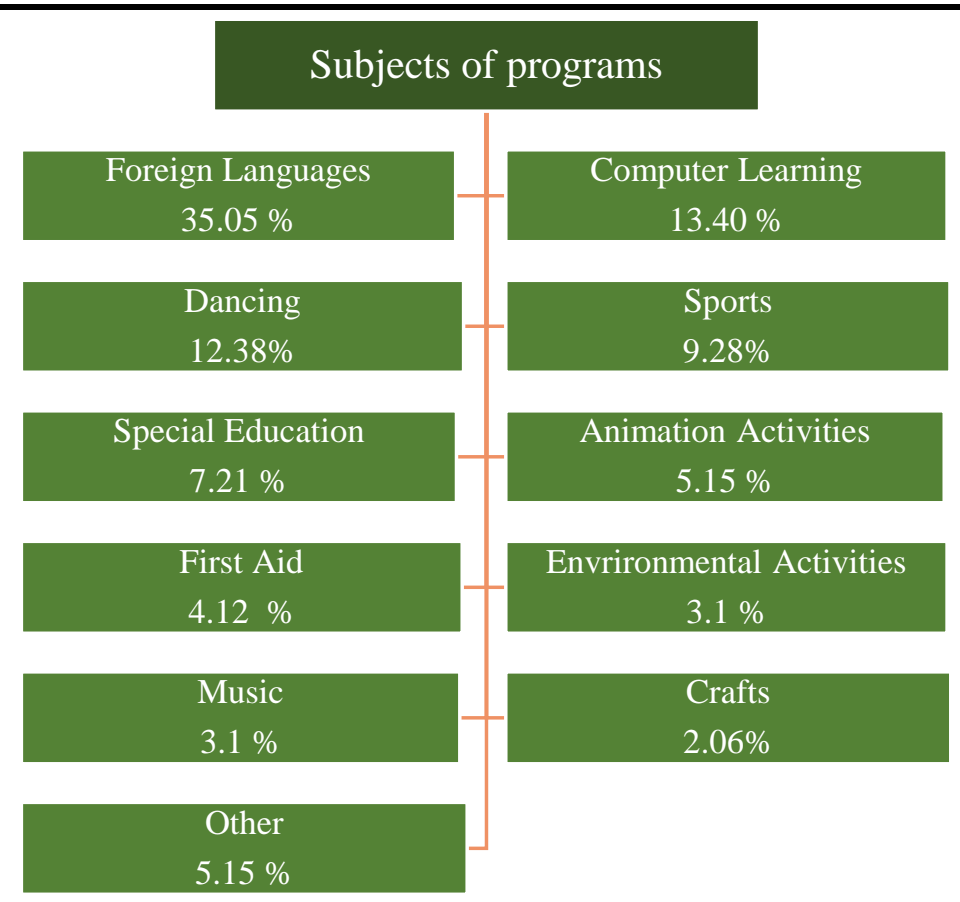

Figure 2: Content of non-formal education programs in which students participate

According to the data, foreign languages are the most preferred type among students $(35.05 \%)$, who recognize the need to communicate in languages other than their mother tongue in the context of globalization and professional mobility, as well as to facilitate their academic needs. A typical quote from participant L19's response is that "in the context of globalization and professional mobility, I consider being fluent in the most widely spoken language, English, to be an essential asset for my personal and professional life". Participation in computer learning programs is also important $(13.40 \%)$, as students report that "new technologies have permeated all aspects of personal and professional life" (L18). Participation in dance, sports and music, photography, crafts programs can help them obtain a sense of personal fulfillment and make better use of their leisure time, while participation in programs related to special education, intercultural learning, first aid lessons, music therapy, crafts, animation activities, religious education, and environmental activities can contribute both to strengthening their essential qualities as early childhood educators as well as to their self-fulfillment as individual personalities (see Table 1). The specific sub subjects of the programs in which students participate are illustrated in Table 1. 
Table 1: Specific sub subjects of non-formal education programs attended by undergraduate students of the Department of Early Childhood Education

\begin{tabular}{|c|c|}
\hline Main subject of the program & Detailed topics \\
\hline \multirow[t]{7}{*}{ Foreign Languages } & English \\
\hline & Spanish \\
\hline & German \\
\hline & French \\
\hline & Italian \\
\hline & Bulgarian \\
\hline & Arabic \\
\hline \multirow[t]{5}{*}{ Computer Learning } & Word \\
\hline & Excel \\
\hline & Internet \\
\hline & Power Point \\
\hline & AutoCAD \\
\hline \multirow[t]{2}{*}{ Music } & Musical Instrument \\
\hline & Music Therapy \\
\hline \multirow[t]{4}{*}{ Special Education } & Special Education and Training \\
\hline & Integration programs and practices \\
\hline & Signed Language \\
\hline & First Aid for disabled people \\
\hline \multirow[t]{8}{*}{ Sports } & Athletics \\
\hline & Swimming \\
\hline & Rhythmic Gymnastics \\
\hline & Gymnastics \\
\hline & Volleyball \\
\hline & Surfing \\
\hline & Yoga \\
\hline & Kick- boxing \\
\hline \multirow[t]{4}{*}{ Dancing } & Traditional dances \\
\hline & Ballet \\
\hline & Latin \\
\hline & Belly dance \\
\hline \multirow[t]{3}{*}{ Animation Activities } & Puppet theatre \\
\hline & Theatrical games \\
\hline & Painting \\
\hline \multirow[t]{2}{*}{ Environmental Education } & Environmental seminars \\
\hline & Environmental activities \\
\hline \multirow[t]{2}{*}{ Crafts } & Embroidery \\
\hline & Handicrafts with everyday materials \\
\hline \multirow[t]{3}{*}{ First Aid } & First Aid Basics \\
\hline & First aid for toddlers and children \\
\hline & First aid for accompanying persons with disabilities \\
\hline \multirow[t]{4}{*}{ Miscellaneous } & Makeup \\
\hline & Photography: visual literacy \\
\hline & Religious education: program for catechists \\
\hline & Intercultural Education \\
\hline Vocational Training & Baby Nursing \\
\hline
\end{tabular}


The subject of programs in which students participate is directly related to the reasons for attending these programs. The latter are related to their studies and profession, their interest in the subject, the creative use of their leisure time, the selffulfillment of their personality, as well as the creation and development of social relationships. Students state that they attend educational programs for more than one reason, confirming what is reported in the relevant literature (Aslanian \& Brieckel, 1980; Karalis, 2021). Their goal to enhance their CV with formal qualifications prompts them to attend foreign language (mainly English) and computer learning programs which equip them with the relevant certifications, that will facilitate a future job search. Language learning, as stated by students, helps them acquire better access to bibliographical sources for the preparation of their work at the university and continue their studies at postgraduate level, facilitating them regarding their participation in Erasmus programs. As far as social relationships are concerned, several students stated that they attended a program because it was co-attended by other members of their family or friends and that they wanted to create and develop social networks through their participation. As stated by a participant (L36) "an important motivation was also to socialize and develop relationships through the program", while L52 stated that "without it being an element of the program, I consider it equally important that I shared this experience with my mother, which prompted me to join her in participating and that has strengthened our relationship". The subjects of the programs chosen by students are often related to their personal improvement so that they can better fulfil their role as early childhood educators. One participant (L44) specifically comments on the special education program she attended: "One reason I attended the program was to learn more about people with special education needs and to mitigate and minimize any preconceptions I may have had." Participant L10, who attended a program on analyzing journalistic images and photographs, has stated: "I learned how to objectively analyze images and news, how to present important issues (i.e., war) to children through activities. I acquired critical thinking towards news reception and the analysis of digital images, in order to avoid misinformation and propaganda".

The main objectives that emerged in relation to the reasons for students to attend the programs are presented in Table 2.

The reasons behind which the students who participated in the study attend nonformal education programs are found in line with the reasons outlined in the relevant literature and are mainly related to their profession directly or indirectly, but also to their interest in lifelong learning and education, the better use of their free time and the creation and development of social relationships (Boshier, 1971; Boshier \& Collins, 1985; Morstain \& Smart, 1974; Cross, 1981; Fujita-Starck, 1996; Karalis, 2021). Furthermore, as students move throughout their period of studies, their reasons for participating in programs are also linked to their academic identity and aim at facilitating and improving their university attendance. It is worth pointing out that the students, according to their statements, do not only anticipate acquiring instrumental learning but they also 
recognize and seek the humanistic dimension of learning, that of communicative and emancipatory learning (Habermas, 1978; Rogers, 2002).

Table 2: Reasons for attending non-formal education programs

\begin{tabular}{|c|c|c|c|c|c|c|}
\hline Academic & \multicolumn{3}{|c|}{$\begin{array}{l}\text { Facilitating the preparation of } \\
\text { projects, finding, and studying } \\
\text { literature }\end{array}$} & \multicolumn{2}{|c|}{$\begin{array}{l}\text { Preparing for } \\
\text { participation in the } \\
\text { Erasmus program }\end{array}$} & $\begin{array}{l}\text { Boosting their } \\
\text { academic profile for } \\
\text { MA applications }\end{array}$ \\
\hline \multirow[t]{4}{*}{ Professional } & \multirow[t]{4}{*}{$\begin{array}{l}\text { Strengthening } \\
\text { essential skills }\end{array}$} & \multicolumn{2}{|c|}{$\begin{array}{l}\text { Learning } \\
\text { things that } \\
\text { will be } \\
\text { useful to } \\
\text { them as } \\
\text { kindergarten } \\
\text { teachers }\end{array}$} & \multirow{4}{*}{\multicolumn{2}{|c|}{$\begin{array}{l}\text { Enhancing typical } \\
\text { qualifications }\end{array}$}} & \multirow[t]{2}{*}{$\begin{array}{l}\text { Certification of } \\
\text { qualifications }\end{array}$} \\
\hline & & \multirow{2}{*}{\multicolumn{2}{|c|}{$\begin{array}{l}\text { Changing } \\
\text { attitudes } \\
\text { Tolerance to } \\
\text { difference }\end{array}$}} & & & \\
\hline & & & & & & \multirow{2}{*}{ CV enhancement } \\
\hline & & \multicolumn{2}{|c|}{$\begin{array}{l}\text { Soft skills } \\
\text { development }\end{array}$} & & & \\
\hline $\begin{array}{l}\text { Interest in } \\
\text { the subject }\end{array}$ & $\begin{array}{l}\text { Related to } \\
\text { their profession }\end{array}$ & \multicolumn{3}{|c|}{$\begin{array}{l}\text { Related to the joy of } \\
\text { learning new things }\end{array}$} & $\begin{array}{l}\text { Related to } \\
\text { their } \\
\text { personality } \\
\text { self } \\
\text { fulfilment }\end{array}$ & $\begin{array}{l}\text { Related to their } \\
\text { physical condition }\end{array}$ \\
\hline $\begin{array}{l}\text { Better use of } \\
\text { leisure time }\end{array}$ & \multicolumn{3}{|c|}{ Pandemic time period } & \multicolumn{3}{|c|}{$\begin{array}{l}\text { They do not have many family and } \\
\text { professional obligations }\end{array}$} \\
\hline $\begin{array}{l}\text { Positive attitude } \\
\text { towards lifelong } \\
\text { education and } \\
\text { learning }\end{array}$ & \multicolumn{2}{|c|}{$\begin{array}{l}\text { Learning and education } \\
\text { is a continuous process }\end{array}$} & \multicolumn{3}{|c|}{$\begin{array}{l}\text { Interest in acquiring new } \\
\text { knowledge and skills }\end{array}$} & $\begin{array}{l}\text { Broadening horizons } \\
\text { through learning }\end{array}$ \\
\hline Self-fulfilment & \multicolumn{3}{|c|}{ Broadening horizons } & \multicolumn{2}{|c|}{$\begin{array}{l}\text { Soft skills } \\
\text { development }\end{array}$} & $\begin{array}{l}\text { Tolerance to } \\
\text { difference, } \\
\text { development of } \\
\text { empathy }\end{array}$ \\
\hline $\begin{array}{l}\text { Social } \\
\text { relationships }\end{array}$ & \multicolumn{3}{|c|}{$\begin{array}{l}\text { Attendance with relatives or } \\
\text { friends }\end{array}$} & \multicolumn{2}{|c|}{ Socialization } & $\begin{array}{l}\text { Social Networks } \\
\text { creation and } \\
\text { development }\end{array}$ \\
\hline
\end{tabular}

In terms of the importance of learning outcomes from their participation in non-formal education programs, students focus on attitude change and the role it plays in improving their personal, student, professional and social lives and development. Indicative responses can be found below: "In general, I consider that what I gained from my participation in the program is very important for both my personal and professional development" (L5), "At a personal level, I gained more confidence and self-esteem, I broadened my intellectual horizons and acquired new ways of thinking. Finally, I came to respect differences and appreciate people with 
PARTICIPATION OF UNIVERSITY STUDENTS IN NON-FORMAL LIFELONG LEARNING PROGRAMS: TYPES OF PROGRAMS, REASONS FOR PARTICIPATION AND THE IMPORTANCE OF LEARNING OUTCOMES IN THEIR STUDENT, PROFESSIONAL, PERSONAL, AND SOCIAL LIFE

different cultures and lifestyles" (L75) and "I participated in a network of social creativity and got to better know the human presence in my neighborhood. I developed friendly relationships with my trainer and some ladies/neighbors in a warm gathering place" (L89). Those who chose to attend programs related to music and dance reported developing soft skills and other important elements for their personality. Indicative responses come for participant L36, according to whom "such programs offer attitudes such as: cooperation, respect for culture and art and adopting artistic sensibility", or participant L45 stating that "the attitudes and values I have acquired help me to strive with perseverance and persistence when setting a goal in my life and also to cooperate with others in order to achieve a goal more easily and effectively" and lastly as stated in participant L82's words "by attending the program I became familiar with the notions of organization and discipline, movement management and control, how to work in a team while preserving my individuality, how to pay more attention to my surroundings and process my immediate environment, I gained body flexibility and balance and I also learned that physical health is very important. What I learned, I consider important because it is a part of my character and myself." Similarly, participant L84, who attended a first aid program, was of the same opinion in that "the attitudes I acquired were mutual help, empathy, support for my fellow people, and even encouragement, meaning to encourage people to help if they can, without second thoughts and without fear. I consider these attitudes very important because they made me a better person".

In the list of the benefits gained from their participation in the programs, students mention that it is of high importance for them to be able to directly apply what they learned in their daily life as teachers, facilitating their work, which is in line with what is mentioned in the adult education literature about the direct application and usefulness of the knowledge and skills that adults acquire in educational programs (Knowles, 1978; Rogers, 2004, 2007). Participant L97, indicatively stated: "The importance of this knowledge, skills and attitudes that I have acquired through this training program lies mainly in the acquisition of specialized ways of managing the needs that arise within a classroom and the problems that occur within everyday educational activity. Also, everything that I brought with me from this program was immediately implementable and effective". In relation to computers, the students clearly use the knowledge and skills acquired for their university studies and as it was mentioned "I consider the computer skills I acquired to be particularly important, as the use of technology and especially the computer use is a key skill nowadays both in the field of personal and professional terrain. It helps me a lot in the preparation of assignments and their presentations, for example with power point software" (L28). Students also associate their studies with the benefits gained from learning foreign languages, e.g., searching for bibliographic sources on the Internet, writing papers, studying resources in other languages: "... it has helped me to search and study scholar papers more effectively, which is a very important asset for a student" (L49). In particular, as regards foreign languages, it should be noted that the students justify their significance not only on their being able to communicate both orally and in writing in another language but also on their coming in contact and acquiring knowledge on different cultures and developing a critical thinking and a positive attitude towards difference: "It is important knowledge, as by learning a foreign 
language, you not only learn how to be fluent in using it, but you also learn about new cultures, customs and ways of life" (L34), "through knowing a language other than your mother tongue, you broaden your horizons and understand the differences and similarities between people" (L5), "To be honest, I consider the attitudes I have acquired along the way to be the most important, and this is because they have helped me to develop, to shape my personality, to sharpen my critical thinking and above all to accept and respect all people and admire all the languages of the world" (L24).

\title{
5. Conclusion
}

Undergraduate students take advantage of the opportunities offered by lifelong learning, participating in non-formal education programs, to respond to new demands that arise in the course of their lives, acquiring new knowledge and skills or updating existing ones. Their reasons for choosing the programs they attend are mainly related to knowledge, skills and attitudes that will complement their university education and facilitate their studies, but also enhance their formal and substantive qualifications as early childhood educators. In addition, students participate in programs to make creative use their leisure time in objects of study that interest them, to create and further strengthen their social networks and for the joy of learning. Regarding the significance of learning outcomes, students focus mainly on the attitudes and skills acquired, making it clear that beyond instrumental knowledge, they look forward to communicative and emancipatory knowledge which they consider to be of high importance.

\section{Acknowledgements}

We would like to thank all the students who participated in this study.

\section{Conflict of Interest Statement}

The authors declare no conflicts of interest.

\begin{abstract}
About the Author
Maria Pavlis-Korres obtained a university degree in Political Science in Athens. From 1983 until 2018 she worked on Adult Education in the Greek Ministry of Education. Since 2005 her research interests are focused on e-learning and she became a PhD student in the University of Alcalá, Spain. In 2008 she obtained her Advance Studies Degree from the Computer Science Department of the University of Alcalá and in 2010 she obtained her PhD with honors. Since 2012 she is a member of the scientific staff of Hellenic Open University and teaches in "Adult Education" and "Education Science" postgraduate programs. In June 2017 she has been elected Associate Professor in the Pedagogical Sector of the Aristotle University of Thessaloniki to teach "Lifelong Learning and non-Formal Education". She has published several articles, chapters and books on Roma, adult education and e-learning. Her current interests are focused on design, development and
\end{abstract}


evaluation of educational projects for adults, face to face and e-learning, as well as the group dynamics in an online environment and the appropriate use of communication tools in order to promote interaction in an online environment.

\section{References}

Aslanian, C. B., \& Brickell, H. M. (1980). Americans in Transition: Life Changes as Reasons for Adult Learning. New York: Future Directions for a Learning Society, College Board.

Boshier, R. (1971). Motivational orientations of Adult Education participants: A factor analytic exploration of Houle's typology. Adult Education Journal, 21(2), 3-26.

Boshier, R., Collins J. B. (1985). The Houle typology after twenty-two years: A large scale empirical test. Adult Education Quarterly, 35(3), 113-130.

Braun, V., \& Clarke, V. (2013). Successful qualitative research: A practical guide for beginners. SAGE Publications Ltd.

Coombs, P. H., \& Ahmed, M. (1974). Attacking Rural Poverty: How Non-formal Education Can Help. Baltimore: Johns Hopkins University Press.

Cross, P., K. (1981). Adults as learners: increasing participation and facilitating learning. San Francisco: Jossey-Bass.

Dourgounas, G. (2021). Educational policy for Lifelong Learning. Athens: National Documentation Centre. E-book (in Greek).

EurCouncil, Doc. 8595, Report 15 Dec, 1999. Non formal education. Committee on Culture and Education. Rapporteur: Mr Cristian Dumitrescu, Romania, Socialist Group.

European Commission/EACEA/Eurydice (2021). Adult Education and Training in Europe: Building inclusive pathways to skills and qualifications. Eurydice Report. Luxembourg: Publications Office of the European Union.

Fujita-Starck, P. J. (1996). Motivations and characteristics of Adult Students: Factor stability and construct validity of the Educational Participation Scale. Adult Education Quarterly, 47(1), 29-40.

Habermas, J. (1978). Knowledge and Human Interest. London: Heinemann.

Jarvis, P. (2002). International Dictionary of Adult and Continuing Education. London: Kogan Page.

Karalis, Th. (2021). Motives and barriers for the participation of adults in Lifelong Education (2011-2019). Athens: IME G.S.E.V.E.E. - INE G.S.E.E. (in Greek).

Knowles, M. S., Holton III, E. F., \& Swanson, R. A. (1998). The adult learner: The definitive classic in adult education and human resource development. Houston: Gulf Publishing Company.

London, J. (1970). The influence of social class behaviour upon adult education participation. Adult Education Quartely, 20, 140-153. 
Morstain, B. R., \& Smart, J. C. (1974). Reasons for Participation in Adult Education Courses: A Multitivariate Analysis of Group Differences. Adult Education, 24(2), 83-98.

Knipparth, H. and DeRick, K. (2015). How social and human capital predict participation in lifelong learning: A longitudinal data analyis. Adult Education Quarterly, 65, pp. 50-66.

Pavlis Korres, M., \& Leftheriotou, P. (2020). Design of Face to Face and E-learning non-Formal Education Programs for Adults. Athens: Ypsilon. (in Greek).

Rogers, A. (2002). Learning and adult education. In R. Harrison, F. Reeve, A. Hanson, and J. Clarke (Eds), Supporting Lifelong Learning (vol. 1) (pp. 8-24). London and New York: Routledge Falmer.

Rogers, A. (2004). Non - Formal Education. Flexible schooling or participatory education? China: CERC Studies in Comparative Education 15. ISBN 0-387-24636-3.

Rogers, A. (2007). Teaching Adults. Open University Press.

Rogers, A., \& Horrocks, N. (2010). Teaching Adults (4 ${ }^{\text {th }}$ ed.). UK: Open University Press.

Tough, A. (1968). Why Adults Learn: a Study of the Major Reasons for Beginning and Continuing a Learning Project. Toronto: Ontario Institute for Studies in Education. UNESCO (2012). International Standard Classification of Education. ISCED 2011. Canada: UNESCO-UIS. 
PARTICIPATION OF UNIVERSITY STUDENTS IN NON-FORMAL LIFELONG LEARNING PROGRAMS: TYPES OF PROGRAMS, REASONS FOR PARTICIPATION AND THE IMPORTANCE OF LEARNING OUTCOMES IN THEIR STUDENT, PROFESSIONAL, PERSONAL, AND SOCIAL LIFE to copy, distribute, transmit or adapt the article content, providing a proper, prominent and unambiguous attribution to the authors in a manner that makes clear that the materials are being reused under permission of a Creative Commons License. Views, opinions and conclusions expressed in this research article are views, opinions and conclusions of the author(s). Open Access Publishing Group and European Journal of Education Studies shall not be responsible or answerable for any loss, damage or liability caused in relation to/arising out of conflicts of interest, copyright violations and inappropriate or inaccurate use of any kind content related or integrated into the research work. All the published works are meeting the Open Access Publishing requirements and can be freely accessed, shared, modified, distributed and used in educational, commercial and non-commercial purposes under a Creative Commons Attribution 4.0 International License (CC BY 4.0). 